This is an Accepted Manuscript/Postprint of an article published by Taylor \& Francis in CONTINUUM. JOURNAL OF MEDIA \& CULTURAL STUDIES on 14 July 2019, available online:

http://www.tandfonline.com/doi/10.1080/10304312.2019.1641180

To cite this article:

Alberto N. García (2019). 'Hannibal and the paradox of disgust,'

Continuum, 33:5, 554-564, DOI:

$10.1080 / 10304312.2019 .1641180$ 


\section{Hannibal and the Paradox of Disgust}

Hannibal (NBC 2013-15) is a bloody and violent television series that also displays an embellished and self-consciously expressive visual style. This article explores the disparity between aesthetic pleasure and repugnance, an issue that scholars working in aesthetic theory have dubbed the "paradox of disgust'. It begins by focusing on the specific qualities of disgust among the so-called 'negative' emotions in art, and develops this analysis through a close reading of significant scenes in Hannibal. Drawing on Strohl's 'hedonic ambivalence', the article argues that Hannibal intensifies its aesthetic value precisely by visually boosting the paradox of disgust, maximizing both aversion and pleasure simultaneously. However, the article also shows that Hannibal attempts to circumvent the paradox of disgust by prompting an 'aestheticist turn', embodied in the experience of protagonist Will Graham.

Key words: Hannibal; disgust; emotions; aesthetics; television studies.

\section{Introduction}

In one of the earliest scholarly essays published on the NBC television series Hannibal, Angela Ndalianis comments on Dr. Hannibal Lecter's gruesome actions: 'His killing and cannibalism are great creations that Hannibal perceives as pure acts of art that tell a story about art and the senses, death and life' $(2015,281)$. This may seem to be an odd coupling: bloody carnage as the pinnacle of artistic enjoyment. Similar assessments can be found in several recent articles on Hannibal: 'horrific tableau' (Schwegler-Castañer 2018, 12-13), 'artistic tableaux of the dead' (Abbott 2018a, 129), and 'diabolical beauty' (Logsdon 2017, 56). By way of Hannibal and its scholarly reception, this article explores a wider problem in the philosophy of art: how does natural aversion become a matter of aesthetic delight?

To work through this problem, I will focus on how Hannibal thematizes the socalled paradox of disgust. Although there are nuances that differentiate them, I will use 'disgust', 'aversion', 'abhorrence', and 'detestation' as broad synonyms. According to Irons, there 'are all emotions of repugnance. They are feelings in reference to some object which is regarded as repulsive and give rise to actions of withdrawal or avoidance' (1987, 
640). To explore these emotions from the viewpoint of artistic works, I begin here by following Korsmeyer's aesthetic theory and delve into the paradox of negative emotions - namely, the enjoyment of painful feelings through an aesthetic experience. Subsequently, I will draw on 'hedonic ambivalence', a concept developed by philosopher Matthew Strohl, to name the pleasure one can obtain from painful experiences. Placing Strohl's theory in dialogue with iconic sequences from Hannibal, the article shows how the narrative heightens its aesthetic value by visually amplifying the paradox of disgust. In the final section, I explore how the concluding episodes to Hannibal offer a kind of solution to the paradox, suggesting that a viewer's own ethical barriers to the enjoyment of violence can be 'conquered' through a unique capacity for empathy held by protagonist Will Graham, characterized by Ndalianis as 'our doorway' into 'both Hannibal and Hannibal's masterful style and affective power' (Ndalianis 2015, 283).

\section{Negative emotions and the paradox of fiction}

How is it possible to enjoy, voluntarily, stories and works of art that engender emotions such as anguish, grief or disgust? Why do some people deliberately engage with artworks that create emotions which they may find objectionable in other spheres of life? This study sorts the different responses to the paradox of negative emotions - encompassing both the paradox of tragedy and the paradox of disgust - into three categories: the imaginative solution, the compensatory solution, and the hedonistic solution. In the first instance, the imaginative response (Walton 1990) suggests that we do not actually feel negative emotions when faced with these works of art, but rather only imagine feeling them. That imagination can be pleasant given the safety net between reality and representation. Second, the compensatory response (Feagin 1983; Carroll 1990) argues that we indeed perceive negative emotions, but that they are a kind of toll that must be paid on the road to achieving a full aesthetic experience. These negative emotions are necessary for the cognitive enjoyment of the overall work of art. However, it is the third category - the hedonistic response - to which I turn here, for reasons that will become apparent in the closer treatment of Hannibal.

In a recent contribution to an intellectual tradition that focuses on 'hedonism' at the centre of aesthetic experience, Carolyn Korsmeyer explores a 'tug of war' that she labels 
the 'paradox of aversion'. Instead of putting the stress on 'pleasure', she prefers the more comprehensive notion of 'the aesthetic', 1 emphasizing 'the capacity of disgust to impart an intuitive, felt grasp of the significance of its object' $(2011,8)$. Disgust does not elicit pleasure per se, but a kind of broader aesthetic experience. In this context, Korsmeyer construes art in a wide-ranging sense, including not only painting, sculpture, and literature, but also food, television and films. Throughout, she notes that while the emotions provoked by a given work of art might be uncomfortable, the discomfort makes them valuable: 'Disgust is not just the nasty price that must be endured to achieve the point of the work; the emotion itself delivers the point' $(2012,760)$. That is, the 'hedonistic' response does not deny the negative aspects of particular emotional experiences, but instead proposes that the reflective assessment of those emotions can, in the right circumstances, be desirable. Disgust may thereby amplify the aesthetic experience, making it more intense by forcing the viewer to calibrate the contradiction between pleasure and rejection: ' $[\mathrm{I}] \mathrm{t}$ is aversion with a backward glance, lingering over and even savoring its object' (Korsmeyer 2008, 373).

However, it may be that even if artworks can elicit an idea or memory of disgust, we do not desire artworks to actually be, in themselves, repugnant or repulsing (see Hanich 2010, 94). For example, one may enjoy the visual depiction of rotting flesh in horror cinema, but have no desire to smell the stench of decay of rotting flesh. This tension highlights the complexity of the 'aesthetic' as both a sensory and a reflective experience. Given its visceral nature, disgust exemplifies the dense network of cognitive operations, emotions, gradations, and nuances that come into play when evaluating a work of art. For these reasons, artists sometimes get the balance wrong: if the work is too sickening, the

${ }^{1}$ In his recent Aesthetic Evaluation and Film, Andrew Klevan tackles the difference between concepts such as evaluation, pleasure and value. In a similar fashion to Korsmeyer, Klevan writes, 'Aesthetics does not discount or demean moral, political, emotional, cognitive, or conceptual content. [...] But the engagement will be with the value of its expression through the form of the work' $(2018,20$, emphasis in original). 
result is not an intense aesthetic experience but merely repugnance and recoil ${ }^{2}$. In this context, I argue below that Hannibal achieves a proper and aesthetically enhanced balance. As Schwegler-Castañer puts it in her study on the entangling of aesthetic taste and conceptual metaphors of consumption in Hannibal, the 'literalization of cannibalism in association to the aesthetic of the show creates an effect of the appetizing yet repulsive by its juxtaposition of beauty and terror' $(2018,15)$. I will unpack how this juxtaposition of gorgeousness and dread functions in Bryan Fuller's television series.

\section{Hannibal and the dichotomy between art and the macabre}

Hannibal was both a reboot and a prequel of the fictional universe novelized by Thomas Harris and adapted for the big screen by Jonathan Demme and Ridley Scott. Will Graham is the main character of the show. He works as a criminal profiler, helping the FBI hunt serial killers. Will has an exceptional psychological gift that he displays in the murder case that launches every week's episode-when visiting the crime scene, he can mentally reenact the killer's modus operandi. During its 39 episodes, Hannibal basked in a kind of horrid imagery that is unusual on free-to-air, contemporary television, including scenes like a giant heart made of human flesh trotting like an elk, a baby inside a 'pregnant' pig, or an eel drowning a disfigured and hideous character. These three examples are among the most notorious in the series, but they are hardly exceptional. Each episode contains scenes of violence and beauty woven together, and the dramatized mise-en-scène of each week's gruesome murder runs as the series' dominant aesthetic paradigm. As Stacey Abbott puts it, 'These crime scenes blur the lines between science, art and macabre display, particularly when examined through the eyes of Hannibal Lecter' (2018b, 559). In-depth analysis of one example from Hannibal can illustrate this dichotomy between art and the macabre (Abbott), and between beauty and terror (Schwegler-Castañer).

2 There have always been reports of cinema spectators physically suffering from disturbing images by vomiting, fainting, or becoming dizzy. Sometimes, especially recently, producers themselves boast of these reports as a morbid marketing tool for films such as Grave (Julia Ducournau 2016), Bite (Chad Archibald 2015), Saw III (Darren Lynn Bousman 2006), etc. (see Crucchiola 2016). 
One of the most iconic, ghastly murders from season one is the 'human cello' found in 'Fromage' (1.8.). The killer - eventually discovered to be Hannibal Lecter himself punishes the least talented musician in the Baltimore Orchestra by shoving a cello neck down his throat and using his vocal cords to play the 'new' instrument. This savage crime neatly illustrates Schwegler-Castañer's argument that Dr. Lecter's crimes interweave aesthetic taste with 'tangible' taste in his killings: 'Hannibal considers that he improves people by converting them into art by "elevating" them into his artistic creations in the form of food or into installation artworks with his theatrical exposition of their corpses' $(2018,7)$. Bryan Fuller's 'theatrical exposition' of the human cello brings an aura of ornate symbolism, aesthetic sophistication, and formal beauty to what may otherwise be experienced as repulsive. This happens in three ways.

Firstly, Hannibal draws regularly on symbolism. The human cello is the epitome of the grotesque, which Carroll understands as the 'feature of combining elements from different biological or ontological orders in a single composite being' $(2003,307)$. The grotesque often appears throughout the series as the intermingling of human and animal, such as the skull converted into a beehive in 'Takiawase' (2.4.), or the corpse strung up emulating a dragonfly ('Secondo', 3.3.). At other times, Hannibal intermixes botanical themes through the corpses, such as victims buried alive and subsequently used as compost to cultivate mushrooms ('Amuse-Bouche', 2.2.). Secondly, the whole scene acts as a performance to the cube. There are three levels of discourse superimposed, resonating with each other: the auditorium as a physical and specific place where the musicians play, the crime scene as a macabre theatre where the serial killer ostentatiously exhibits his twisted artistry, and the empathetic performance, through which Will Graham reenacts the process of the murder - including, in turn, a short 'cello' musical act by Will himself. Furthermore, the multiplication of performances provides the sequence with a high degree of structural and aesthetic complexity, so that the viewer is never required to focus solely on the grisly aspects of the murder. Thirdly, visual design is central to the framing of 'disgusting' violence in the human cello sequence. As Abbott puts it, Hannibal follows an aesthetic drive already present at The Silence of the Lambs (1991), where the dead from the crime scenes are repeatedly presented as figures of 'macabre beauty' (2018b, 558). From its beginning, the scene shows a visual balance: a long shot shows the whole auditorium-a 
clean, quiet, and magnificent location. The crime scene is highlighted by a zenithal beam that projects a perfect circle of light in the centre of the stage. The spotlight becomes more intense as Will begins his 'performance' by re-enacting the slicing and impaling of the musician.

[Figure 2 near here. Caption: Graham plays a cello neck in 'Fromage.' Credit: NBC]

Will discovers the modus operandi of the killer and his final goal: 'Powder on the wound. Rosin from the bow. I wanted to play him. I wanted to create a sound. My sound'. Accordingly, Will 'plays' the human cello. The ominous music transforms into a solo, and the mise-en-scène conveys a crane tilt pan linking the close-up of the cello to a long shot of the stalls. There lurks the hallucination of Garrett Jacob Hobbs, the serial killer from the pilot episode, who is alone in the auditorium, clapping under the spotlight. Taken together, this densely packed aesthetic experience subsumes and enhances the primal effect that repugnance could have upon the spectator, because the disgusting elements are layered among several other aesthetic devices, as I will detail henceforth.

\section{Hedonic ambivalence, context and absorption in Hannibal}

Through its mise-en-scène and its narrative content, Hannibal deliberately maximizes both disgust and aesthetic enjoyment. To understand how the 'contradictory' elements of key sequences in Hannibal might function together, I turn here to Matthew Strohl, who makes a compelling theoretical argument to account for a contradiction that he terms as 'hedonic ambivalence' $(2012,203)$. Strohl tackles the complexity of the issue by suggesting a structural difference between 'atomic' and 'complex' experiences. The former refers to discrete, isolated sensations such as smelling a particular scent, while the latter includes a variety of thoughts and perceptions that accumulate and interrelate, such as the complex experience of watching a film. 'A complex experience', Strohl writes, 'has the pleasure structure partly in virtue of one or more of its elements (complex or atomic) having the pain structure' (209-10). This argument shared affinities with Kieran's argument that 'what is normally repellent and harsh to look upon may, given a certain context and relation to other features, become beautiful and pleasing' (Kieran 1997, 392). In Strohl's 
development of this theme, he proposes 'the possibility that a pain structure can be embedded within a pleasure structure' (2012, 209, emphasis in original). An artwork offers a 'hedonic ambivalence' when the overall pleasure provoked is due, at least in part, to the pain/disgust provided by one of its atomic elements:

Pain can be attractive when it synergizes with other elements of a complex experience to make that experience more pleasant. The attractiveness of a painful emotion as such is not due to its intrinsic phenomenal character, but rather to the relation that this character bears to other aspects of the experience it is an element of. (Strohl 2012, 210)

A close reading of the unnamed couple assassinated in the episode of Hannibal entitled 'Primavera' (3.2.) illustrates the ways that relational assessment can help to transform repugnance into beauty.

After awakening from his coma, Will Graham has travelled to Italy, where Hannibal Lecter has escaped from the Federal Bureau of Investigation (FBI) with his psychiatrist and lover, Bedelia du Maurier. Graham meets there inspector Rinaldo Pazzi, who believes Lecter is related to an old criminal he pursued two decades ago, Il Mostro. Hannibal's earlier crimes come to mind because the corpses of a loving couple have been displayed in a style resembling an allegorical Renaissance painting, 'Spring' (1477-1482), by quattrocento Italian artist Sandro Botticelli. The two unnamed lover are physically used to replicate the right-hand corner from Boticelli's tempera on panel - in a sense, the corpses are both decontextualized and re-contextualized. The display copies Botticelli to an excruciating detail: the tunics, the physical position, the blue tint for the Zephyrus-like figure, the yellow tone for Chloris, and the flowers coming out of her mouth. Following Strohl's theory, an unsettling encounter with two dead bodies could be understood as an 'atomic' experience that is then subsumed within a 'complex' experience. Mise-en-scène and intertextuality make the implied violence seem both more pleasant and more intense, such that '[one] finds oneself in certain contexts attracted to a feeling that outside such contexts one is categorically averse to' $(2012,203)$. 
[Figure 3 near here. Caption: A murder à la Boticcelli in 'Primavera.' Credit: NBC]

The brilliance of the mise-en-scène allows the viewer to focus on the physical characteristics of the objects displays, and to suspend or defer feelings of disgust and repugnance. 'We can be absorbed in either type of experience,' writes Strohl, 'but our absorption has a positive character in the aesthetic cases. It is in virtue of this positive character, not in virtue of our absorption, that these experiences count as pleasant' (2012, 207). The notion of fascinated absorption also influences the viewer not only to tolerate, but also to engage aesthetically, with scenes that feature disgusting acts. A final example from Hannibal episode 'Futamono' (2.6.) helps to show how such devices work across the series.

Will Graham is incarcerated, and Hannibal has just survived a murder attempt. The focus of the episode is the killing of Sheldon Isley, a councilor from Baltimore who had approved the construction of a parking lot in an area full of songbirds. After declaring to Alana Bloom that he needs 'to get' his 'appetite back', Hannibal picks up a business card (Sheldon Isley) from his wheeldex and a recipe (steak and kidney pie) from his box. Brian Reitzell's musical score commences, deploying metal sounds and a grinding melody. An extreme close-up from Hannibal's eye dissolves into yellow stamens. The tune unnervingly intensifies while the montage sequence exhibits a succession of colourful, vivid flowers in the process of blossoming. One shot rapidly dissolves into the next. A dolly shot moves the camera away from what seems to be a stunning bouquet. The camera calmly moving out reveals the ominous location of the bouquet inside an eviscerated body. The flowers are 'replacing' the internal organs, save for the lungs. The whole body is grafted to a tree, so that the human body resembles the central trunk. The cadaver's arms merge with the branches and its feet with the roots. The dolly track ends in a long shot, so that the surroundings of the 'Tree Man' are visible, and it is revealed that the grotesque sculpture has been placed in the middle of an empty parking lot, foggy in the background. This recalls Caspar David Friedrich's landscapes, as if the killing were in the middle of a romantic vision. The colour palette is pale and subdued, so that the brightness of the flowers contrast with the rest of the image. 
[Figure 4 near here. Caption: The grotesque 'Tree Man' in 'Futamono.' Credit: NBC]

In this sequence, absorption is not achieved through the empty shock value of the cadaver image. Instead, it is elicited through the violent and gorgeous expressionism found in the sequence's mise-en-scène, which plunges the viewer into a universe of madness, allowing for what, following Strohl, could be understood as a complexification of the atomic horror at the centre of the display. A nightmarish pre-opening credits montage that exhibits a texture of operatic sophistication, sweet dream, and irresistible delicacy.

\section{Circumventing the paradox: Will's aestheticist turn}

I have so far explored how Hannibal's 'hedonic ambivalence' allows us to make sense of the narrative's seemingly contradictory mix of aesthetic splendor and abhorrence. Nevertheless, Hannibal does propose a way to surmount the paradox of disgust, and to understand this, we need to consider the ethical dimensions of the program. Given Dr. Lecter's despicable actions, as well as murders carried out by other screen villains, how do ethical considerations shape the aesthetic synthesis of disgusting and beautiful images?

From a symbolic point of view, Dr. Lecter's anthropophagy epitomizes a victory of aesthetics over ethics. Bedelia de Murier puts it bluntly at the beginning of her Italian journey when she states, 'You no longer have ethical concerns, Hannibal. Only aesthetical ones' (3.1.). When cooking and tasting human organs, Lecter radically refutes any kind of moral contradiction, because he rejects the first premise of the paradox, that is, that human innards are somehow disgusting. He dismembers human bodies as part of an artistic composition and cooks organs with the devotion of a gifted chef. Beyond clinical diagnosis, the Nietzschean Hannibal Lecter fits the definition of aestheticism, a philosophy of life and

of art. In a book devoted to the issue, Robert Vincent Johnson offers an account of its main features:

The work [of art] is not to be valued for anything that could influence our conduct or even our general attitude to life; it is to be valued solely for the immediate aesthetic pleasure it affords (2017, 14, emphasis added) 
One of the narrative features of Hannibal is Lecter's tendency to deploy double meanings in his speech and to hint at extra-textual irony. During the pilot, after an intense first encounter at Jack Crawford's office, this dialogue takes place between the two protagonists:

HANNIBAL LECTER: I would apologize for my analytical ambush, but I know I will soon be apologizing again, and you'll tire of that eventually, so I have to consider using apologies sparingly.

WILL GRAHAM: Just keep it professional.

HANNIBAL LECTER: Or we could socialize, like adults. God forbid we become friendly.

WILl GRAHAM: I don't find you that interesting. HANNIBAL LECTER: You will.

This early exchange can be understood as an anticipatory meta-commentary on how the narrative requests the spectator to adapt to Hannibal's 'hedonic ambivalence'. The narrative invites the audience to find the gruesome scenes more and more enjoyable and 'interesting', and Lecter's call to friendliness grows in parallel with the cultivation of visual absorption as a key aesthetic device across the series. In the 'complex internal structure' that every Hannibal sequence contains, the 'hedonic ambivalence' also overrides painful or problematic 'atomic' elements that are embedded within, such as the wicked ethics of Lecter's horrendous crimes. The story does not end until the protagonist Will Graham can overcome the paradox of disgust for himself.

Will teams with Hannibal to slay the fearsome Red Dragon. In his last scene with Hannibal, Will points out that they share a true communion based on aesthetics, resonating Johnson's aestheticist conviction 'that the enjoyment of beauty can by itself give value and meaning to life' $(2017,10)$ :

HANNIBAL LeCTER: This is all I ever wanted for you, Will. For both of us. WILL GRAHAM: It's beautiful! 
They have their arms around each other's shoulders and together plummet off a cliff. The very relationship between Will and Hannibal, the thread that weaves through the series' three seasons, replicates the duality between fascination and repulsion that characterizes the labyrinth of disgust in art. In this way, the story ends with Lecter's victory, which amounts to an aesthetic triumph, insofar as Will clears his own ethical concerns by killing the Red Dragon without experiencing any moral discomfort. In his own 'aestheticist turn', Will drastically divorces art from life, in the spirit characterized by Johnson: 'art has no reference to life, therefore no moral implications' (Johnson 2017, 13).

During the pilot, Dr. Lecter had already warned Jack Crawford about Will's power: 'What he has is pure empathy. He can assume your point of view, or mine - and maybe some other points of view that scare him' (1.1.). The fatal farewell of Will and Hannibal suggests that, at last, Will can maximize his own aesthetic pleasure, notwithstanding the disgust felt in relation to the sinister artwork - the murder of Red Dragon - he had 'created' alongside Dr. Lecter. Will's enraptured statement - 'it's beautiful' — shows that morally murky villains and dainty slasher scenes can be, indeed, highly enjoyable when one puts aside ethical considerations. Will finally finds magnificence in violence and killing. His face and clothes are blood-splattered after the savage brawl with the Red Dragon, yet he lovingly hugs the depraved Dr. Lecter. In this way, Hannibal poses questions regarding limits of empathy and its implications for aesthetic pleasure. In her essay on ethics, imagination and intercoporeality in Hannibal, Stadler suggests that through its 'complex aesthetic and narrative evocation of disgust and the theme of cannibalistic incorporation, the television series explicitly invites its audience and its characters to consider themselves and their own bodily relationships to empathic feelings, sensory perception, and imagination' $(2017,416)$. In this context, we can ask: does the audience follow Graham in this last aestheticist turn? Can the spectator share Will's ecstasy after having killed the Red Dragon and having found it so beautiful?

\section{Conclusion}

NBC's visual nightmare Hannibal stands out as a crowning moment in the aesthetics of disgust in contemporary television culture. The characteristics of Gothic horror that Bruhm describes (1994, xvii) resonate in the 'beautiful barbarity' and 'troublesome power' that 
Hannibal depicts. Its craving for style engenders exuberant visual imagery, where fear, pain, and disgust are adorned with an exquisite beauty that alludes to Botticelli's allegorical compositions, Friedrich's landscape paintings, or a virtuoso cello performance, to cite some intertexts analyzed earlier.

As Schwegler-Castañer asserts, 'Hannibal embodies binaries and by uniting them, questions them' $(2018,12)$. In presenting the disgusting, the atrocious, and the grisly as beautiful, Hannibal and Hannibal force the viewer to question the limits of aesthetic enjoyment, and potentially allow for a more 'complex' experience, in the sense given by Strohl. The interrelation between beauty and abhorrence developed during gory Hannibal sequences establishes an intense 'hedonic ambivalence', such that disgust makes 'an active contribution to the pleasant character of the complex experience it is embedded in' (Strohl 2012, 210). For this reason, Hannibal offers a fascinating dramatisation of the repugnant in contemporary television, turning Gothic horror into what might be characterized as artistic Darwinism: only the greatest aesthetes can survive.

\section{References}

Abbott, S. 2018a. 'Masters of Mise-en-Scène: The Stylistic Excess of Hannibal.' In Horror Television in the Age of Consumption. Edited by K. Jackson, and L. Belau, 126140. New York: Routledge.

Abbott, S. 2018b. 'Not Just Another Serial Killer Show: Hannibal, Complexity, and the Televisual Palimpsest.' Quarterly Review of Film and Video 35 (6): 552-567. doi: 10.1080/10509208.2018.1499348

Bruhm, S. 1994. Gothic Bodies: The Politics of Pain in Romantic Fiction. Philadelphia: University of Pennsylvania Press.

Carroll, N. 1990. The Philosophy of Horror; or, Paradoxes of the Heart. New York: Routledge.

Carroll, N. 2003. 'The grotesque today: Preliminary notes toward a taxonomy.' In Modern Art and the Grotesque. Edited by F. S. Connelly, 291-311. Cambridge: Cambridge University Press.

Crucchiola, J. 2016. 'Raw and 15 Other Horror Movies That Physically Sickened Audiences.' Vulture. September 15. Accessed 12 January 2018. 
http://www.vulture.com/2016/09/raw-antichrist-history-of-movies-that-sickenedaudiences.html

Feagin, S. L. 1983. 'The pleasures of tragedy.' American Philosophical Quarterly 20 (1): 95-104.

Hanich, J. 2010. Cinematic Emotion in Horror Films and Thrillers: The Aesthetic Paradox of Pleasurable Fear. New York: Routledge. doi: 10.4324/9780203854587

Irons, D. 1987. 'The Primary Emotions.' The Philosophical Review 6 (6): 626-45.

Johnson, R. V. (1969) 2017. Aestheticism. London: Routledge. doi: $10.4324 / 9781315314723$

Kieran, M. 1997. 'Aesthetic Value: Beauty, Ugliness and Incoherence.' Philosophy 72 (281): 383-99.

Klevan, A. 2018. Aesthetic Evaluation and Film. Manchester: Manchester UP. doi: 10.7765/9781526132567.00006

Korsmeyer, C. 2008. 'Fear and Disgust: The Sublime and the Sublate.' Revue Internationale de philosophie 246: 367-79.

Korsmeyer, C. 2011. Savoring Disgust. The Foul and the Fair in Aesthetics. New York: Oxford University Press. doi:10.1093/acprof:oso/9780199756940.001.0001

Korsmeyer, C. 2012. 'Disgust and Aesthetics.' Philosophy Compass 7 (11): 753-761. doi: 10.1111/j.1747-9991.2012.00522.x

Logsdon, R. 2017. 'Merging with the Darkness: An Examination of the Aesthetics of Collusion in NBC's Hannibal.' The Journal of American Culture 40 (1): 50-65. doi: 10.1111/jacc. 12678

Ndalianis, A. 2015. 'Hannibal: A disturbing feast for the senses.' Journal of Visual Culture 14 (3): 279-84. doi: 10.1177/1470412915607928

Schwegler-Castañer, A. 2018. 'The Art of Tasting Corpses: the Conceptual Metaphor of Consumption in Hannibal.' Continuиm 32 (5): 611-28. doi:10.1080/10304312.2018.1499874

Stadler, J. 2017. 'The Empath and the Psychopath: Ethics, Imagination, and Intercorporeality in Bryan Fuller's Hannibal.' Film-Philosophy 21 (3): 410-27. doi: 10.3366/film.2017.0058 
Strohl, M. 2012. 'Horror and Hedonic Ambivalence.' The Journal of Aesthetics and Art Criticism 70 (2): 203-12. doi: 10.1111/j.1540-6245.2012.01512.x

Walton, K. L. 1990. Mimesis as Make-Believe: On the Foundations of the Representational Arts. Cambridge: Harvard University Press. 